\title{
Evaluation of School Learning: The Pedagogical Alignment of Evaluation Practices
}

Eliabe Bezerra de Oliveira Silva ${ }^{1}$ Abstract: This article deals with the relation between evaluation of school
performance and other types of evaluation. The purpose of this paper is not
to propose internal school evaluation as the central axis in the teaching-
learning process, considering the ethical, political, pedagogical and social
aspects throughout the evaluation process. The method was the direct
observation of the evaluation routines, in state schools of Juazeiro do Norte-
Ceará. Bibliographic research was also used to interpret the content. The
arguments were constructed in order to renew the discussion on the subject,
making possible new relations. The results led us to believe that the
pedagogical alignment of school evaluation with other types of evaluation is
an essential tool within a systemic view of education. There are
interchangeable relations between these evaluations, with implications in the
relations among the social actors, in a quest for social equity. Therefore, the
bases of school evaluation tend to change, starting from an ethical and
political stance, that begin at the local level, within the school. All forms of
evaluation, internal and eternal, should contribute to consolidate the circle of
communication between the social actors involved in schooling and to "feed"
an information network in order to support more effective public education
policies. Keywords: Evaluation. Learning. School. Policies.

\section{Introduction}

It is known that education reflects ethical stance and political choice. Thus, it is necessary to add to the academic discussions the reflection about the evaluation of school learning as an articulator of other evaluations of the educational universe and as a cooperator for the formation of a new awareness about the political-pedagogical project, the institutional evaluation and the external evaluations that have a public policy aspect. In this article, it is proposed that the change in the quality of the entire evaluation process, both internal and external, has as its starting point the evaluation of school learning, resized in its philosophicalpolitical aspect.

\footnotetext{
${ }^{1}$ Professor of Portuguese Language in the public education network of the State of Ceará, specialist in Clinical and Institutional Psychopedagogy, musician and Masters in Education by Anne Sullivan University.
} 
Evaluative practices are not new activities in the history of humanity, nor in the history of Brazil. It is correct to affirm that today there is a culture of evaluation rooted in several human activities that directly or indirectly involve the learning of some knowledge or task, not only in the school reality. This culture has become multifaceted and increasingly complex.

In classical Greco-Roman antiquity, when school emerges as a privileged place for the acquisition of knowledge, evaluation appears as a need to measure knowledge and to judge moral and philosophical behaviors and positions. Then, in the eighteenth century, still as a privileged place and within the incipient educational systems, the school receives the children of the decadent nobility and incorporates the children of the ascendant bourgeoisie, and continues to be a stage of evaluation, which includes the quality of the systems themselves.

The historical time was in charge of showing the dialectic between evaluation as an activity linked to the ontological vocation of man to seek to be more than he is, to go beyond and to seek improvement (Freire, 1996), that is, evaluation as a projective activity that points the way ahead; and, in parallel, its use as a mechanism of judgment, measurement or punishment, and hence instrument for the maintenance of relations of power and control by the ruling classes.

Although it is no longer the only space that disseminates socially constructed knowledge, since it divides this responsibility with other instances such as cultural centers, associations, unions, churches and virtual communities, the school is still the articulating space of knowledge whose today social dynamics reaches scale unprecedented before 1970 due to the new information and communication technologies that accelerate the historical march of cosmopolitanism and globalizing capitalism.

In this context of shared importance of the school, three types of evaluation characterize the Brazilian school education scenario and its systems: the educational evaluation, internal and external, and the institutional evaluation. The present study focuses on the internal educational evaluation, also known as school evaluation or evaluation of school performance.

Considering the numerous published works on this theme, the differential of the proposal of this article is in its objective: to reflect on the evaluation of school learning as a 
focal point or node in the articulation of other evaluations of the educational universe, and as a cooperative element for the formation of a new awareness about the political-pedagogical project of the school, the institutional evaluation and the external evaluations, which have the character of public policy.

In order to better organize the argumentation and thematic progression, the following points were highlighted: the first presents paradigms and conceptions of education and school evaluation that permeate pedagogical discourses; the second supports the proposal of pedagogical alignment between the school evaluation, with the instruments of evaluation of income, and the institutional and external evaluations; the third one, as an illustration of the proposal presented in the previous section, is the scale of evaluation of school performance presented by the Federal University of Ceará by Dr. Leonel Correia Pinto, from the Federal University of Ceará, and published by McDonald (2003). Finally, the results of the research and the conclusion are presented.

\section{Paradigms and educational concepts in school evaluation}

When traversing the paths of the Brazilian educational evaluation, we highlight the legacy of the tests of content reproduction from Jesuit and Herbtist pedagogies, and the heritage of US psychometry and technobureaucracy. On the technical side, both inheritances are considered traditional, but coexist with other cultural references in relation to evaluation. This is enough, as an analysis, to demonstrate initially the complex and multifaceted nature of school evaluation in the history of Brazilian education.

Under the political-pedagogical aspect, two paradigmatic tendencies coexist in Brazilian school reality, as a result of the plurality of pedagogical and evaluative currents, and also the political tension of its historically situated forces: the direct reproduction of social inequalities through the methodological proposal of teaching and of the traditional evaluative practices, that is, consonant with the practices mentioned in the previous paragraph; Or the contrast between the methodological proposal of teaching with alternative or experimental pedagogy and the evaluation practices, which could translate into contradiction between discourse and practice. 
When there is no dialogism between discourse and practice, or theory and practice (thus, it can be treated as applied theory), there are pedagogical customs that permeate the speeches of educational professionals, which label the pedagogical practices of constructivists, technicists, cognitivists, interactionists, as if these adjectives were "identification cards" and proof of the method used.

Such studies or theories need to pass through the sieve of contextual analysis, which necessarily includes at least two contexts: that of the author of the study and that of the school reality. And this contextualization cannot be imposed by programs or projects elaborated by funding agencies and educational consulting firms in the service of the public power; Rather, it must pass through the analysis of the teaching collegiate, which will do the direct interpretation and mediation of the program with the students.

Another necessary relation is that between evaluation - treated as a great process that includes the types mentioned in this work - and curricular movement. The formulation and definition of the curriculum, mirrored in the Political Pedagogical Project, maintains a symbiotic relationship with school evaluation and other types of evaluation. The evaluation process is revealed in the curricular movement, that is, the evaluation structure is effective in the daily school life and it is updated in the social dynamics that the community makes with the curriculum knowledge.

These relations, in turn, have epistemological and methodological implications, since it updates the dialogism between theory and practice, or theory and methodology conceived as applied theory. The school evaluates in the same sense the conception of education that is rooted in it.

If this ingrained conception no longer meets society's demand, then it is necessary to break it; And the transformation does not occur without learning to look differently for knowledge, curriculum and assessment.

Even in the knowledge that change, in order to be full, has to reach the macro level of public education policies in general, and public education policies in particular - change must begin at the micro level of the school and the community. This is the proposal for school education, involving evaluation and curriculum.

Obstacles that prevent such changes are the paralysis of the Political Pedagogical Project, the absence of a systemic construct, composed by the updating of teaching knowledge, critical awareness of educational programs and policies in the historical march of 
education, and efficiency in pedagogical planning and evaluations. Responsibility for these obstacles is fully shared by all actors involved in the education universe.

The positivist and cartesian instrumentalism that presents itself in school activism, its routine and embedded practices that reflect paralyzing paradigms and attitudes against change, also contributes to the lack of initiative to experience these relationships, which are essential so that the school does not remain the environment relatively "insulated" of social processes that put scientific knowledge in constant circulation.

The problem with customs is that they do not allow us to break this technical instrumentalism of the school because they are the result of superficial readings and quick contacts with theories, studies and approaches without provoking structural or paradigmatic changes in the political-pedagogical posture and technique. This is very common in Brazil and sheds light on another theme: the formation of teachers, needing some time for curricular changes and social articulation.

The dichotomy "traditional pedagogy and experimental or alternative pedagogy" is very strong both in the academy and in the collegiate of school teachers, being relevant its discussion in this section. The history of Brazilian education and the history of university education in Brazil contribute together to highlight the pedagogical eclecticism without any clarification and awareness about the theoretical references that in the past have consolidated teaching practices that are still present today. In addition to eclecticism, there are pedagogical experiences reportedly following educational theorists which reveal pedagogical polarization.

Brazilian education through eclecticism and the plurality of pedagogical ideas has both positive and negative aspects. Methodological freedom in school education is positive in a democracy. However, eclecticism without clear awareness of a guiding axis of pedagogical ideas generates actions devoid of creative intentionality, low efficacy and efficiency in pedagogical planning and in the evaluation process, as well as the risk of alienation of those who exercise education closely - teachers and students - and possible political opportunism in the elaboration of public education programs, projects and policies that benefit dominant groups.

The plurality of pedagogical ideas and practices, including school evaluation, points to theoretical references that in the past were reaching Brazil. The most remote, well before the Brazilian Republic, is the Jesuit pedagogy, which exerted influence in the lay teacher of the First Republic many years after the expulsion of the Jesuit priests in 1759 by the Marquês de 
Pombal's reform. Until today it is possible to perceive the presence of educational and religious precepts of the Jesuits and elements of didactic regiment of the Companhia de Jesus, concretized in the Ratio Studiorum due to the influence of Catholicism and its practices rooted in culture.

At present, factors such as attention, perseverance, emulation - learning by imitation of models of exemplary authors - obedience and meritocracy are still valued in teaching. These elements were part of the Jesuit ideology and were the guiding axis of the evaluative process. Nevertheless, there are other notable influences that also had some of these elements.

According to Ghiraldelli Jr. (1990), although Brazilian pedagogy owes much to these principles of Jesuitism, "it is not correct to affirm the identity between Traditional Pedagogy and Jesuit Pedagogy. Traditional Pedagogy was, in fact, composed of modern American and German pedagogical theories, with a common substrate in Herbatism."

It should be remembered that the pedagogy of a religious and catholic nature - with strong Jesuit traits -, the pedagogy of religious-protestant nature - with contained expression -, Traditional Pedagogy, Libertarian Pedagogy - with a socialist and anarcho-syndicalist background - and Pedagogy of New School formed the educational scene of the first decades of the twentieth century, although its influences are directly related to economic, social and political fluctuations and gained different notoriety.

With this last term, the author refers to the pedagogy of the German philosopher Johann Friedrich Herbart (1776-1841) and his followers, as the educator Francis Parker for example. American educators who were in Germany made contact with the Herbatism and published extensive literature in respect to which, in part, arrived in Brazil during the First Republic through intellectuals like Rui Barbosa.

Knowing the growing influence of psychology in education, and also considering the strengthening of scientific status in the nineteenth and twentieth centuries, it is not surprising to know that educational theorists such as Johann Heinrich Pestalozzi (1746-1827) and Herbart encouraged the tendency to "psychologize the education".

Herbart's pedagogy emphasizes the three stages of character development - sensation, perception and impulsivity (1o); Memory and imagination (2o); And judgment and universal concepts (3o); It should be noted, in addition, the principle of instructional education and one of the most famous teaching methods, the five formal steps to teach classes: preparation, presentation, association, generalization and application. There was also the cult of rigor and 
discipline, but the curricular organization was derived from positivism, which gave rise to criticism from other pedagogies.

With regard to school evaluation and evaluation of the quality of teaching, examination and certification were institutionalized as evaluation practices in the USA, France and Portugal, for example, starting in the eighteenth century and especially in the nineteenth century with the consolidation of educational systems, which grew progressively, keeping up with the historical march of globalizing capitalism and the need of governments to form leaders who perpetuated the control of the means of production by the ruling class and the more skilled labor to serve this ruling class.

The departure of the school marked the transition to social life and the professional future to follow. This scenario prevailed in the urban environment; Countries with late industrialization were still predominantly rural at this time, with very few schools in the interiors. This is the case in Brazil.

In this context, two paradigms of education and evaluation of school performance coexisted: one that already saw the exam as a methodological problem and revealing problems in the pedagogical practice, with reference in Comenius ${ }^{1}$, and another that considered it practice of supervision in the perspective of control of Performance of the individual and the system visualizing a future certification.

It is worth remembering that the concept of examination is linked to the measurement of learning and to the performance of tests, grades, assessment of skills, programs, methods and curricula. The instrumental evaluative rationality that until today is remarkable in the school evaluations, mainly through the tests and the grades, as it is seen, is tributary of the Docimology, considered by its creators as the science of the evaluation, whose models refer to the presuppositions of experimental Psychology of the 20th century.

The core problem of these instrumentalist and experimental theories is that they focus the discussion on school evaluation only in the technical aspects, seeking a scientific "proof" to the use of the instrument. Thus, they reduce large-scale social problems to technical problems (GURGEL, 2003, p.71).

By disregarding other dimensions interfering in the evaluation process, they conceal the social problems that affect the learning subjects and the school community. As an instrument of school evaluation, the predominance of pedagogical evidence, which has

\footnotetext{
${ }^{1}$ João Amos Comenius wrote "Didactic Magna" in 1657 and defended individuality and freedom in learning. 20 
Docimology as a reference rooted in the evaluative culture, masks variables such as stereotypy and halo representations of those who correct the tests, and also disregarding pedagogical problems in the teaching-learning process.

Therefore, the evaluative examination practices have many cultural references, which makes it difficult to know the exact degree of their influences, but does not prevent to conclude that such practices exist today, alongside new theories and new evaluation approaches based on other references, which need to be analyzed.

\section{School evaluation and external evaluations: alignment required}

Before any consideration, it is worth mentioning that Brazilian public school education and its education systems operate around the axis "State as an evaluator". In addition, in the public school the figure of the evaluating State is present and manifested through the modus operandi controller and instrumentalist, that is, that is done with instruments of management and expenses control, projects, programs and time.

Taking evaluation as a control - a reductionist and tributary perspective also to Cartesian positivism - this State that evaluates can sometimes be allied to the market, or it can be allied to the society. In the first case, the most recurrent in the history of Brazilian education, public policies are conditioned or fostered by funding agencies of school education, which have been active in Brazil for decades. In the second case, the state recognizes and supports the population on its agenda of demands for quality education and social equity.

External evaluations, or large-scale ones, are public policies for education and evaluation in which educational systems and institutions are evaluated in terms of student learning. In general, their focus is the assessment of the quality of education systems, and certification or selection for another level of study, thus also assessing students' academic performance.

The problem of exam pedagogy, even in more refined formats such as the Exame Nacional do Ensino Médio (ENEM) (National High School Examination), is the notorious neglect of teacher training problems in order to know better the methodology of this type of test, and the neglect of cognitive and learning problems of students (GURGEL, 2003, p.73). 
The history of education in Brazil reveals that public education has reached a school for masses level, a term that generates controversies and questions about the quality of education. The gradual process of universalization of basic education is linked to the history of capitalism in the country, where progress and setbacks towards democracy are evident in access to a free, quality, secular school.

In this context, large-scale public evaluation policies such as the ENEM, for example, are historically the best way for the evaluation of lifelong learning and the quality of basic education, in regard of the transition of young students to higher education.

This does not exempt it from criticism as to the pedagogical and political use of the results of this examination, nor with respect to the methodology used in its elaboration, common in similar tests at federal and state level, such as SAEB and SPAECE, respectively.

As for the first aspect, pedagogical and political, the lack of knowledge by the teachers to take advantage of the results of the ENEM and other similar exams for the replanning and improvement of the didactic sequence is a structural problem in teaching, related to the neglect of the public power regarding concrete incentive for continuous training of these teachers in order to better deal with the results of their evaluation practices and better interpretation of public education policies.

Consequently, the absence of teacher training for the concrete knowledge of the public policies of evaluation and the interpretation and use of the results also makes it difficult to align these external examinations with the other types of evaluation already mentioned, the institutional evaluation and the school evaluation.

Regarding the second aspect, the methodology, considered by experts as the vanguard in the paradigm of inter-trans-multidisciplinarity and perfected since its first edition in 1998, has suffered in the last editions a setback for submitting questions of content order (memorization of information, concepts and contents), that is, in the style of old university entrance exams methodologies in the country, which still exist, in less number since the enlargement of the ENEM as a general policy for access to university level.

In short, the predominant scenario in internal school assessments in public schools is that these are going in one direction, the verification of content-based and fragmented learning, through the use of mathematical grades and averages, without using these results to improve the teaching-learning, which would be, in fact, to evaluate; And external evaluations 
are moving in another direction, approaching the integrative perspective of knowledge - intertrans-multidisciplinary.

Today, MEC and INEP, in partnership with funding agencies that also do educational consulting, prepare the external evaluations. If schools fail to live up to expectations, they are held accountable for political management. The policy of meritocracy in using the results of large-scale examinations is explicit or veiled, but exists and grows mainly at the state and municipal levels.

Scientific research and even simple queries on institutional sites of management disclosure - in state or municipal level - reveal that the results of these evaluations end up feeding much more the quantitative aspect than the qualitative one, giving margin to the sensationalism on the statistics for the purpose of political promotion of management, and the appropriation of these statistics to create competitiveness between school units of the same system and to implement a meritocracy policy, thus favoring only a few.

The scenario outlined above on large-scale assessments shows some reasons why it is difficult to align this type of assessment with the type of internal assessment that usually appears in most Brazilian public schools. The proposed school performance assessment, which will be presented below, will illustrate a possible path based on the cognitive sciences and will allow for the construction of inicial criticisms and conclusions.

\section{The Natural Assessment Scale of Human Learning: proposal under analysis}

It is reiterated that, in this section, there is no intention of transmitting a formula or instructing evaluative technique to be applied orthodoxly in the classroom by the teacher. It will now be shown the proposal of school evaluation elaborated by professor Leonel Correia Pinto, from the Federal University of Ceará, and published by McDonald (2003, pp. 30-51).

Next, considerations will be made regarding the positive and negative aspects of this proposal, taking it as an illustration for the analysis of the condition of pedagogical alignment between the evaluation of school performance and other types of evaluation considered in this work, such as the institutional evaluation and external or large-scale assessments, addressed in their status as public educational policies.

At first glance, the natural scale of assessment is pedagogically daring, since it starts from a premise more accepted by the cognitive sciences, but questioned by teachers as to its 
applicability: it is possible to capture the direction and intensity of the human learning development's process, in any level at which it is being carried out.

There is also the assumption that unobservable school learning does not mean absence of learning - the author of the scale denies absolute zero - nor does it mean that it will not be observable learning later when the student reaches the point of cognitive maturity for what is assessed. The influence of Piagetian psychogenesis (KESSELRING, 1993), whose paradigm is that biological maturity comes before the development of intelligence and learning, is perceived in this assumption.

Vygotsky's psychogenetic view is added in this work, that in this respect, is opposed to that of Piaget and considers that the teacher's mediation, along with the symbolic mediation of verbal and non-verbal languages, can anticipate the development of intelligence and therefore of learning.

In accordance with the premise and assumption mentioned above, the "natural" scale is partially ordered in five points, which reflect the process in progress:

\begin{tabular}{|c|c|c|c|c|}
\hline $1^{\mathrm{o}}$ & $2^{\mathrm{o}}$ & $3^{\mathrm{O}}$ & $4^{\mathrm{o}}$ & $5^{\mathrm{O}}$ \\
\hline $\mathrm{NO}$ & $\mathrm{B}$ & $\mathrm{MB}$ & QA & AUT \\
\hline
\end{tabular}

The above acronyms represent nominally the following: NO, nonobservable learning, that is, there is the assumption of the direction and intensity of the learning, but this is imponderable or not communicable verbally and symbolically, still being able to reflect the inefficacy of the tests; B, good learning, means qualitative and quantitative leap in learning; $\mathrm{MB}$, very good learning, indicates predominance of intensity; In QA, almost autonomous learning, the direction and the intensity are accentuated; And AUT is the mature process, indicating self-motivation, creative attitude on the part of the student, interests and tastes defined in relation to the fields of human knowledge and doing and behavioral maturation.

\section{Results}

After analyzing the proposal in question, it is possible to attest that these concepts are more open and flexible for teacher interpretation and student acceptance than stigmatizing concepts such as bad, weak or insufficient, or the numerically 0-10 scale traditionally adopted 
in the Brazil without the accompaniment of other elements. It also leaves open the possibility of adapting the natural scale to the numerical scale, since private and public education systems, for the most part, require numerical grades for registration and control for approval and certification.

However, it should be noted that the student needs to be fully aware of the meaning of this verification tool within the assessment process, and the implications for him/her, the teacher, and the school community. The perception that every member of the school community makes of the evaluation process and the visible results in the performance verification instruments is conditioned by representations, stigma and stereotypes around the words that define the semantic field of this discussion: education, school, student, teacher, learning and evaluation, each with a historically constructed paradigmatic profile.

It is seen that in this natural scale of evaluation there is influence, although shared with others, of psychometrics, due to the relevance given to the tests as a fundamental element of the evaluation instrument, which can be composed of other concrete / objective elements and abstract / subjective elements such as the student's posture towards knowledge and other behaviors inside and outside the classroom, currently also considered.

There is no infallible school evaluation approach, but the pedagogical alignment with other types of evaluation is indispensable, within a systemic view, because there are interchangeable relations between these evaluations with the political-pedagogical posture of the school and the teacher, and the implications of these relations in the pressures, demands and historical struggles for the re-signification of public policies of education in favor of the quality of education, leading to social equity.

Non-alignment, in turn, renews technicality in the evaluation, which receives many critics for its inoperability in forming critical and participant citizens, the opposite of mere reproducers of historically constructed knowledge. In other words, only the change in the technical form of school evaluation, without dialogue with the systemic whole and without paradigmatic changes, a conjunctural change which does not alter the functioning structure of the evaluative practices. 


\section{Conclusion}

In view of the above, the object of analysis of this article is reiterated, only with an ethical and political attitude the bases of the school evaluation will change. Beginning at the local level, from within the school to the school community. All forms of evaluation need to be fairly aligned.

The re-signification of the Political Pedagogical Project, the Class Councils, the institutional evaluation, the external evaluations and, in some schools, the psychological and psychopedagogical assessments should "feed" the communication circle and the information network about the students. First, because the number of information we have about who we want to evaluate is a decisive factor towards the knowledge of its singularities and the homogenizing position that characterizes Brazilian school education; Second, because having varied instruments with different approaches and types of verification and accompaniment of learning guarantees technical and scientific rigor and approximates the evaluation of the ethical and political perspective of justice and citizenship in education, whose north must surpass the rules of the job market's game.

These factors must be a constant to contribute with information that allows the critical balance between the selection of content, skills and competences that are prioritized for the school community, and those that society demands for the dynamics of social, academic and labor relations. This set of factors also allows the school to be able to form a supportive background or a support for those who need special attention at specific times in the teachinglearning process.

In order to avoid methodological problems and the lack of scientific rigor in this selection, all actors involved in schooling must participate in the selection in order to guarantee the representativeness of the sample, ie that the content, skills and competences parts represent the whole, And do not overlook important learning topics, for example. This usually happens also because few actually participate in the process or it happens in an embarrassing and improvised way.

Hence, the initial planning that includes diagnostic evaluation and the organization of appropriate instruments. It is suggested to include in the diagnostic evaluation the objectives and descriptors linked to the content, not to resume or reproduce the "classic" behavioral model of evaluation by objectives already proposed fifty years ago in the USA by Ralph Tyler 
(Raphael, 1998, 27; HOFFMANN, 1991, p. 39-42), but to make the process more solid, following the line of reasoning here constructed with several factors.

Finally, the focus of this study was fulfilled, which was not to reproduce the types of evaluation using the most recurrent nomenclature in the literature on the subject - diagnostic, formative, summative and emancipatory evaluations, but to advance in the critical reflection on the evaluation process that necessarily have all elements presented and others as researches progress.

\section{References}

Freire, Paulo. (1996) Pedagogia da Autonomia. São Paulo: Paz e Terra.

Ghiraldelli Jr., Paulo. (1990) História da Educação. São Paulo: Cortez.

Gurgel, Carmesina R. (2003) As práticas avaliativas e a evolução de suas funções. In: Andríola, Wagner B.; Mcdonald, Brendan C. (2003) (Orgs.). et al. Avaliação: Fiat Lux em Educação. Fortaleza: Editora UFC.

Hoffman, Jussara. (1991) Avaliação: mito e desafio - uma perspectiva construtivista. Porto Alegre: Mediação.

Kelssering, T. Jean Piaget. (1993) Petrópolis: Vozes.

Mcdonald, Brendan C. Outra opção de avaliação escolar. In: ANDRÍOLA, Wagner Bandeira; McDonald, Brendan Coleman (2003) (Orgs.). et al. Avaliação: Fiat Lux em Educação. Fortaleza: Editora UFC.

Raphael, Hélia S. Avaliação escolar: em busca de sua compreensão. (1998) São Paulo: Brasiliense.

\section{How to cite this article (APA):}

Silva, E.B.O (2017). Evaluation of School Learning: The Pedagogical Alignment of Evaluation Practices. Am. In. Mult. J., March. 1 (2), 14-27. 